\title{
Augmented Renal Clearance in Critically III Patients in Malaysian Intensive Care Unit: Assessment of Prevalence, Risk Factors and Outcomes.
}

\author{
Shahir Asraf b Abdul Rahim ${ }^{1}$, Azrina Md Ralib ${ }^{1}$ \\ ${ }^{1}$ Department of Anaesthesiology and Intensive Care, Kulliyyah of Medicine, \\ International Islamic University Malaysia
}

Presenter: Shahir Asraf b Abdul Rahim

Introduction: Augmented renal clearance (ARC) is a phenomenon where there is elevated renal clearance and defined by creatinine clearance $>130 \mathrm{ml} / \mathrm{min}$. ARC results in changes of the pharmacokinetic and pharmacodynamic of antimicrobial therapy being administered resulting in its subtherapeutic dose. We evaluated the prevalence, risk factors and outcome of ARC in critically ill patients in two Intensive Care Units (ICU) in Kuantan. Materials and Methods: This was a two centre, prospective observational study of critically ill patients. Inclusion criteria were patients older than 15 years old with plasma creatinine $<130 \mu \mathrm{mol} / \mathrm{l}$, with arterial line and urinary catheter inserted. The creatinine clearance $(\mathrm{CrCl})$ were measured using plasma creatinine, urinary creatinine and urinary flow rate. ARC is defined as $\mathrm{CrCl}$ of more $130 \mathrm{ml} / \mathrm{min}$. Results: Among 102 patients recruited, 57 (55.9\%) had ARC. Those with younger age $(39.9 \pm 19$ years old, $p=0.013)$ and lower SOFA score $(2.8 \pm 2.6, p=0.012)$ had increased risk of developing ARC. No significant difference in other risk factors such as male and trauma were found. There was no difference in the ICU and hospital mortality $(p=0.652$ and $p=0.128)$. There was also no difference in the duration of ICU admission amongst survivors with or without ARC (100.6 \pm 142.3$)$. Measured $\mathrm{CrCl}$ correlated well with the estimated glomerular filtration rate (eGFR) using all four different eGFR equations ( $r=0.436$ to 0.552 , $\mathrm{p}<0.0001)$. Conclusion: ARC occurs in almost half of critically ill patients and more common in younger age and lower SOFA score. However, there was no difference in the outcome. eGFR may be used as surrogate in detecting ARC. 